\title{
Comparative Performance Study of Perovskite Solar Cell for Different Electron Transport Materials
}

\author{
Najmin Ara Sultana ${ }^{1}$, Md. Obidul Islam ${ }^{1,2}$, Mainul Hossain ${ }^{* 2}$ and Zahid Hasan Mahmood ${ }^{* 2}$ \\ ${ }^{1}$ Department of Electrical and Electronic Engineering, Hamdard University, Munshiganj-1510, Bangladesh, \\ ${ }^{2}$ Department of Electrical and Electronic Engineering, Dhaka University, Dhaka 1000, Bangladesh
}

(Received: 27 February 2018 ; Accepted : 2 July 2018)

\begin{abstract}
In recent times, planar organo-metal halide perovskite solar cells (PSCs) achieved high power conversion efficiency (PCE > $22 \%$ ). Mixed organic-inorganic halide perovskites, with excellent light harvesting properties, have evolved as a promising class of semiconductors for photovoltaics. In this work, compositional and electrical characterizations of materials used for different layers of PSC have been studied. One dimensional solar cell simulator wx-AMPS is used for numerical simulation of such devices and all simulations are done under AM1.5 illuminations and 300K temperature. Investigating the influences of thickness of electron transport material (ETM), hole transporting material (HTM) and absorber on the photovoltaic performance of PSCs, it is observed that, increase in thickness of perovskite $\left(\mathrm{MAPbI}_{3}\right)$ results in the increase in PCE of solar cells, whereas increase in thickness of ETM layer results in decrease in the efficiency of the devices. The ETM plays a vital role on the performance of PSC. In this paper, for the first time performances of PSC for three different $\mathrm{ETMs}\left(\mathrm{TiO}_{2}\right.$, $\mathrm{ZnO}$ or $\mathrm{SnO}_{2}$ ) are calculated and analyzed simultaneously with the simulator wx-AMPS. The photovoltaic performances have been explored and efficiencies of $27.6 \%, 27.5 \%$ and $28.02 \%$ are reported for perovskite solar cells with $\mathrm{TiO}_{2}, \mathrm{ZnO}$ and $\mathrm{SnO}_{2}$ as ETM respectively for a specific thickness. Finally, this simulation study concludes that $\mathrm{ZnO}$ and $\mathrm{SnO}_{2} \mathrm{may}$ be effective alternatives of the commonly used material, $\mathrm{TiO}_{2}$ as they are economically more potential and give somewhat better photovoltaic performance.
\end{abstract}

Keywords: Perovskite Solar Cell, Electron Transport Material, wx-AMPS.

\section{Introduction}

During the last decade, a new kind of dye-sensitized solar cell (DSSC) has been developed, where a solid hole conducting material is used in place of the liquid electrolyte. Michael Gratzel et al. fabricated solid state DSSCs, by depositing two different solutions of $\mathrm{CH}_{3} \mathrm{NH}_{3} \mathrm{I}$ and $\mathrm{PbI}_{2}$ that form a composite dye of perovskite and achieved $15.0 \%$ of efficiency.

Among existing photovoltaic technologies, perovskite solar cells have unfolded as a promising alternative because of its 'superior optoelectronic behavior, solution-processability and excellent photovoltaic performance. The perovskite acts as a good absorber for solar cells as it has fantastic electron and hole diffusion ability coupled with very wide absorption wavelength range and high photo-conversion efficiency ${ }^{2,4}$. Bach et al. developed the PSC by replacing the liquid-electrolyte with solid-state hole-transporting material (HTM) 2,2' ,7,7' tetrakis (N,N-di-pmethoxyphenyl-amine) $9,9^{\prime}$-spirobifluorene (OMeTAD) ${ }^{5}$.

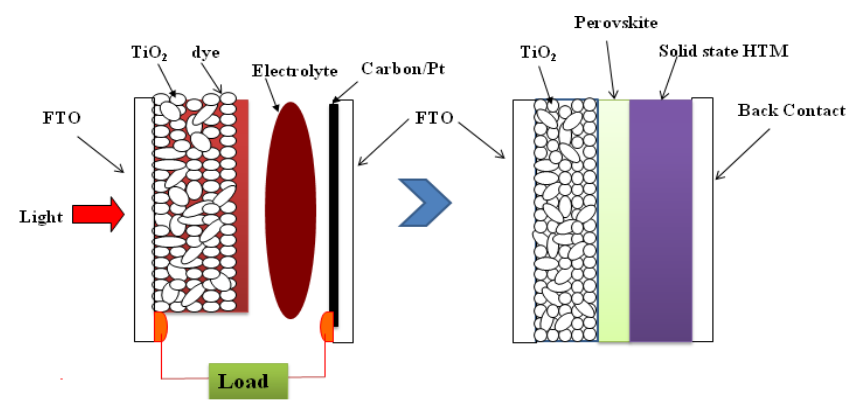

Fig. 1. Perovskite solar cell (Solid State) toDye-sensitized solar cell (Liquid-state).
Fig.1 shows the basic device structure of a liquid-state DSSC and solid-state perovskite solar cells (PSC).Typically, fluorine-doped tin oxide (FTO) serves as the conducting glass substrate for DSSC. The substrate is followed by a $\mathrm{TiO}_{2}$ film, a porous nano-crystalline semiconductor oxide. $\mathrm{TiO}_{2}$ is normally sensitized bi-pyridine ruthenium complexes (dye) which absorbs visible light. The de-oxidized dye is oxidized by a redox electrolyte layer such as iodide/tri-iodide couple. The cathode is coated with platinum to collect electrons and catalyze the redox couple regeneration reaction ${ }^{6}$. Holes are transported to the external circuit as the electrolyte regenerates the oxidized dye and transports the electrons back to the dye molecules.

Traditionally, $\mathrm{CH}_{3} \mathrm{NH}_{3} \mathrm{PbI}_{3}$ (perovskite) has long been used as sensitizer particles in dye-sensitized solar cells (DSSC) with liquid-electrolyte ${ }^{7}$. Due to solvent leakage and corrosion of liquid electrolyte, researchers have been concerned on replacing this liquid electrolyte with a solid hole transporter to create a fully solid-state electronic Dyesensitized solar cells ${ }^{7}$.

Miyasaka et al introduced perovskite in photovoltaics in 2009 and observed efficiency $3.81 \%$ and $3.13 \%$ for $\mathrm{MAPbI}_{3}$ and $\mathrm{MAPbBr}_{3}$ based solar cells, respectively ${ }^{8}$. To this date, efficiencies of DSSCs have reached to $22.1 \%$. However, in terms of efficiencies, cadmium telluride solar cells (CdTe, 19.6\%), copper indium gallium diselenide (CIGS, 21.7\%), crystalline silicon (c-Si, 25\%), and gallium arsenide (GaAs, 28.8\%) ${ }^{10-14}$ still outperform the PSCs. A deeper understanding of the material properties of the individual layers is necessary to explore the possibilities of achieving higher efficiencies in PSCs.

*Author for correspondesnce. e-mail: mainul.eee@du.ac.bd, zahid@du.ac.bd 
In 2013, Mingzhen Liu et al. prepared vapor-deposited FTO/compact $\mathrm{TiO}_{2} / \mathrm{CH}_{3} \mathrm{NH}_{3} \mathrm{PbI}_{3} /$ spiro-OMeTAD/Ag cell and achieved $15.4 \%$ efficiency $^{15}$. In 2014, a planar heterojunction $\mathrm{CH}_{3} \mathrm{NH}_{3} \mathrm{PbI}_{3}$ solar cell with $\mathrm{TiO}_{2}$ (ETM) and spiroOMeTAD (HTM) were simulated with AMPS-1D and obtained $20 \%$ of efficiency by Feng Liu et $a l^{3}$. Weijun Ke et al. used the process of thermal oxidation to grow a thin $\mathrm{TiO}_{2}$ film on the perovskite and prepared a cell that gave substantially high efficiency of $15.07 \%$. In 2015, Jing Wang et $a l^{17}$. reported perovskite solar cells with thin dense Mg-doped $\mathrm{TiO}_{2}$ as hole-blocking layers (HBLs), outperforming solar cells with $\mathrm{TiO}_{2} \mathrm{HBLs}$ due to their higher open-circuit voltage, $\mathrm{V}_{\mathrm{oc}}=1.08 \mathrm{~V}$ and $\mathrm{PCE}$ of $12.28 \%$. Yun-Jeong Kim et $a l^{18}$. applied $\mathrm{CH}_{3} \mathrm{NH}_{3} \mathrm{PbI}_{3}$ (perovskite) to $\mathrm{FTO} /$ glass and $\mathrm{Au} / \mathrm{Ti} /$ polyethylene terephthalate (PET) substrate at $100^{\circ} \mathrm{C}$.Very recently, Ao Zhang et al. achieved $26.6 \%$ of efficiency from $\mathrm{ZnO}(\mathrm{ETM}) / \mathrm{MAPbX}_{3}$ (perovskite)/CuSCN (HTM) -based solar cell ${ }^{19}$.

In this work, a comparative study has been done by replacing $\mathrm{TiO}_{2}$ with $\mathrm{ZnO}$ and $\mathrm{SnO}_{2}$ as ETM layer with perovskite and spiro-OMeTAD. One major challenge of the commercialization of perovskite technology is that its longterm stability under thermal and moisture stresses is somewhat lower than that of inorganic devices. This drawback can be minimized to some extent by increasing the solar cell power conversion efficiency and reducing the fabrication costs. In this paper, it has been shown that efficiency can be improved and cost can be reduced if $\mathrm{TiO}_{2}$ (commonly used ETM with PSC) is replaced with $\mathrm{ZnO}$ or $\mathrm{SnO}_{2}$ as these materials are very cheap and available in market.

\section{Modeling of Perovskite Solar Cell}

In this study a simple model for perovskite solar cell of $\mathrm{p}-\mathrm{i}$ $\mathrm{n}$ device structure is used. The cross-section of this model is shown in Fig.2. The back contact is made of gold. The spiro-OMeTAD layer acts as the HTM and is located on top of the back contact. A low p-type doped perovskite $\left(\mathrm{CH}_{3} \mathrm{NH}_{3} \mathrm{PbI}_{3}\right)$ absorber layer is sandwiched between the $\mathrm{n}$ type material $\left(\mathrm{TiO}_{2}\right)$ and the p-type spiro-OMeTAD layer. Here, $\mathrm{TiO}_{2}$ is used as ETM with Fluorine doped Tin Oxide (FTO) on top.

\begin{tabular}{|c|}
\hline $\mathrm{SnO}_{2}: \mathrm{F}$ (Front Contact) \\
\hline $\mathrm{TiO}_{2}$ (ETM) \\
\hline $\mathrm{CH}_{3} \mathrm{NH}_{3} \mathrm{PbI}_{3}$ (Absorber) \\
\hline Spiro-OMeTAD (HTM) \\
\hline Au (Back Contact) \\
\hline
\end{tabular}

Fig. 2. Cross-sectional schematic diagram of $\mathrm{p}-\mathrm{i}-\mathrm{n}$ perovskite solar cell solar cell.

In solar cell, absorber is important to harvest the energy by controlling doping concentration and charge carrier mobility; surface properties of the ETM and HTM affect the charge carrier conduction between the front and back contacts $^{2}$. Efficient collection of the charge carriers depends on work function of the front contact material and rear metallization. And most importantly the choice of ETM plays a vital role on the design of high efficiency perovskite solar cell as the energy band alignment between absorber and ETM layer is a crucial factor for the efficiency improvement of $\mathrm{PSCs}^{2}$. $\mathrm{TiO}_{2}$ is a semiconducting material and is widely used as ETM or hole-blocking layer with perovskite cells due to its appropriate band gap, electron affinity, large surface area, abundance and process ability in different forms.

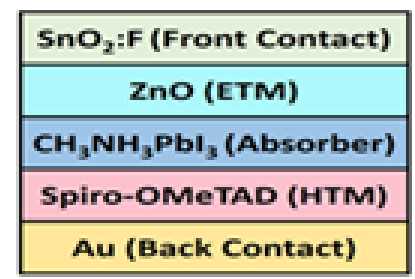

(a)

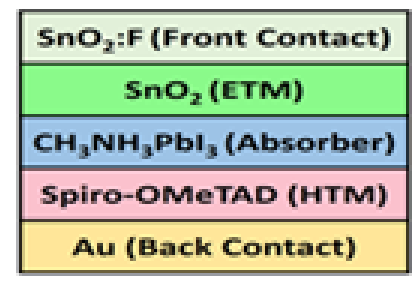

(b)
Fig. 3. (a) Model cell 1: $\mathrm{TiO}_{2}$ is replaced by $\mathrm{ZnO}$ (b) Model cell 2: $\mathrm{TiO}_{2}$ is replaced by $\mathrm{SnO}_{2}$.

Some other mesoporous conducting oxides, $\mathrm{ZnO}$ and $\mathrm{SnO}_{2}$ may be good alternatives when used with $\mathrm{MAPbI}_{3}$ absorber and spiro-OMeTAD, hole transporting material. Fig.3 shows two proposed models, where ETM layer, $\mathrm{TiO}_{2}$ is replaced by $\mathrm{ZnO}$ and $\mathrm{SnO}_{2}$. Photovoltaic performances for PSCs with these three ETMs are determined by varying the thicknesses of absorber layer, ETM layer and HTM layer. FTO is taken as the front contact material as it is widely used with perovskite cell and $\mathrm{Au}$ has been taken as the rare contact.

\section{Numerical Simulation: wx AMPS}

The optimized structure of a PSC has been numerically modeled and simulated by using wx-AMPS (Analysis of Microelectronic and Photonic Structures) solar cell simulation software which is an improved version of AMPS-1D software under AM 1.5 G solar irradiation and $300 \mathrm{~K}$ temperature ${ }^{20}$. At first, optimized metal as back contact for PSC is determined by varying work function. Then optimized cell is obtained by varying ETM, absorber and HTM layer thicknesses. Effects of the variation of different layer thicknesses on photovoltaic performances (open circuit voltage, short circuit current, fill factor and efficiency) are discussed. Three different PSCs have been modeled by replacing ETM layer. Finally comparative discussion on the performances of various models is given with optimized the cell structures.

wx-AMPS solves Poisson's equation and the hole and electron continuity equations. It is one of the reliable computer aided program for modeling various single and multi-junction as well as Schottky barrier devices both in hetero- and homo-structures ${ }^{21}$. The assumptions made on this model are: carrier populations obey MaxwellBoltzmann statistics, the only recombination mechanism is the radiative band-to-band process (monomolecular), 
internal conversion efficiency makes it to $100 \%$ and photon recycling effect appears in the cell. The general form of Poisson's equation is given by equation 1 .

$$
\begin{aligned}
& \frac{d}{d x}\left(-\varepsilon(x) \frac{d v}{d x}\right)=q\left[p(x)-n(x)+N_{D}^{+}(x)-N_{\lambda}^{-}(x)+\right. \\
& \left.p_{t}(x)-n_{t}(x)\right]
\end{aligned}
$$

where, $N_{D}{ }^{+}, N_{A}{ }^{-}$are the concentrations of ionized donors and acceptors, $n, p$ are the free electrons and holes concentrations, $n_{t}, p_{t}$ are the concentrations of trapped electrons and holes, $\varepsilon$ is the dielectric permittivity of semiconductor, $\Psi$ is the electrostatic potential, and $q$ is the charge of the carrier.

Solving the continuity equations provides the transport characteristics of the device. The continuity equations in steady state conditions are:

$$
\begin{aligned}
\frac{1}{q} \frac{d J_{n}}{d x} & =R_{n}(x)-G(x) \\
\frac{1}{q} \frac{d J_{p}}{d x} & =G(x)-R_{p}(x)
\end{aligned}
$$

where, $R_{n}, R_{p}$ are electrons and holes recombination velocities for direct band-to-band and indirect transitions, $J_{n}, J_{p}$ are electron and hole current density, and $\mathrm{G}$ is the optical generation rate which is expressed as a function of $x$ is,

$$
G(x)=-\frac{d}{d x} \sum_{i} \phi_{i}^{F O R}\left(\lambda_{i}\right)+\frac{d}{d x} \sum_{i} \phi_{i}^{R E V}\left(\lambda_{i}\right)
$$

where, $\Phi_{i}^{F O R}$ is the photon flux of the incident light and $\Phi_{i}^{R E V}$ is the photon flux the light reflected from the back surface. Both these parameters are defined at a wavelength, $\lambda$ of $I$ at some point $x . \Phi_{i}^{F O R}$ and $\Phi_{i}^{R E V}$ depend on the absorption and reflectance coefficient of light in the forward and reverse direction, respectively.

Solving equations (1), (2), and (3) yields state variables $\Psi(x)$, the $n$-type quasi-Fermi level $E_{F n}$, and the $p$-type quasi-Fermi level $E_{F p}$ or, equivalently, $\Psi(x), n(x)$, and $p(x)$. These quantities fully define the system at every point $\mathrm{x}$ in the device. Analytical solutions are not possible in this case.

In wx-AMPS, numerical technique, Newton- Raphson method is used and following boundary conditions are applied on the given set of equations ${ }^{23}$ :

$$
\begin{gathered}
\boldsymbol{w}(0)=\boldsymbol{w}_{0}-V \\
\boldsymbol{w}(L)=0 \\
J_{p}(0)=-q S_{p o}\left[p_{o}(0)-p(0)\right] \\
J_{p}(L)=q S_{p L}\left[p(L)-p_{o}(L)\right] \\
J_{n}(0)=q S_{n o}\left[n(0)-n_{o}(0)\right] \\
J_{n}(L)=-q S_{n L}\left[n_{o}(L)-n(L)\right]
\end{gathered}
$$

Here, $S_{p o}$ and $S_{n o}$ represent the effective interface recombination speeds for holes and electrons respectively at $x=0$ and $S_{p L}$ and $S_{n L}$ are effective interface recombination speeds at $x=L$.
Electrostatic potential and the quasi-Fermi level for holes and electrons as a function of depth, at every point in the solar cell, are calculated in the wx-AMPS from the solutions of the three coupled differential equations as described above. Once these parameters are determined, the results can be used to obtain carrier concentrations, electric fields and currents, and device parameters like the open-circuit voltage (Voc), short circuit current density $(\mathrm{Jsc})$, fill-factor (FF), and the efficiency $(\eta)^{23}$.

\section{Result Analysis}

\section{Variation of ETM Thickness}

Fig.4 shows variation of open circuit voltage $\left(\mathrm{V}_{\mathrm{oc}}\right)$, short circuit current density $\left(\mathrm{J}_{\mathrm{sc}}\right)$ and photovoltaic conversion efficiency (PCE) with thickness of ETM layer for three different cells. For three models, $400 \mathrm{~nm}$ thicknesses are taken for both $\mathrm{MAPbI}_{3}$ (absorber) and spiro-OMeTAD (HTM) layer. The thickness of ETM layer is varied from 10 $\mathrm{nm}$ to $450 \mathrm{~nm}$ and gradual decrease of Voc, Jsc and PCE is observed. The overall performance of solar cell with $\mathrm{SnO}_{2}$ as ETM is higher than other two models for the entire thickness range. At lower thickness $(10 \mathrm{~nm}$ to $180 \mathrm{~nm})$, $\mathrm{TiO}_{2}$-based model gives better performance than $\mathrm{ZnO}$ based cell, but for thickness higher than $250 \mathrm{~nm} \mathrm{ZnO-base}$ model shows better efficiency than $\mathrm{TiO}_{2}$. The observation showed that $\mathrm{TiO}_{2}$ is more responsive to sunlight than that of the other two electron collecting materials as it has higher absorption co-efficient and reflectance and less transmittance ${ }^{2}$. It can be easily perceived that the increase in thickness of ETM degrade the performance of the solar cells. This is mostly due to fractional absorption of incident light by ETMs and variation in series resistance of the device with increasing thickness of ETM layer. Although better photovoltaic performances are found at thickness less than $50 \mathrm{~nm}$, considering the chemical and mechanical stability of the device, $90 \mathrm{~nm}$ thickness of ETM may give moderately good result for all the three models. Efficiencies of $27.6 \%, 27.5 \%$ and $28.02 \%$ are found for $\mathrm{TiO}_{2^{-}}, \mathrm{ZnO}$ and $\mathrm{SnO}_{2}$-base cell respectively at $90 \mathrm{~nm}$ thickness of electron collecting material.

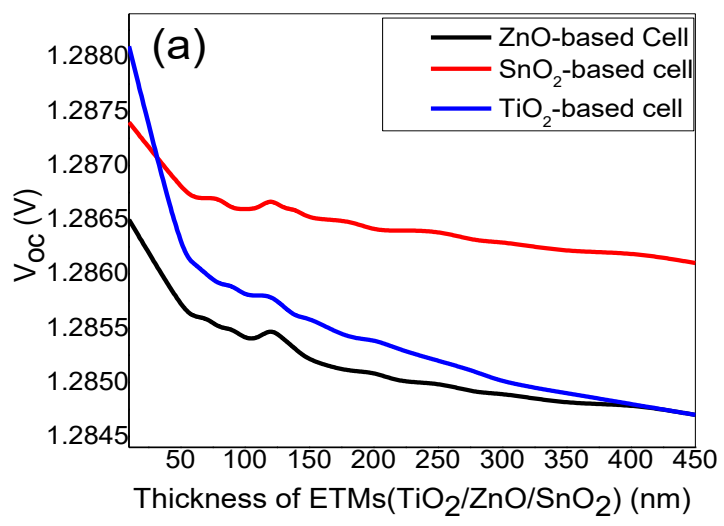



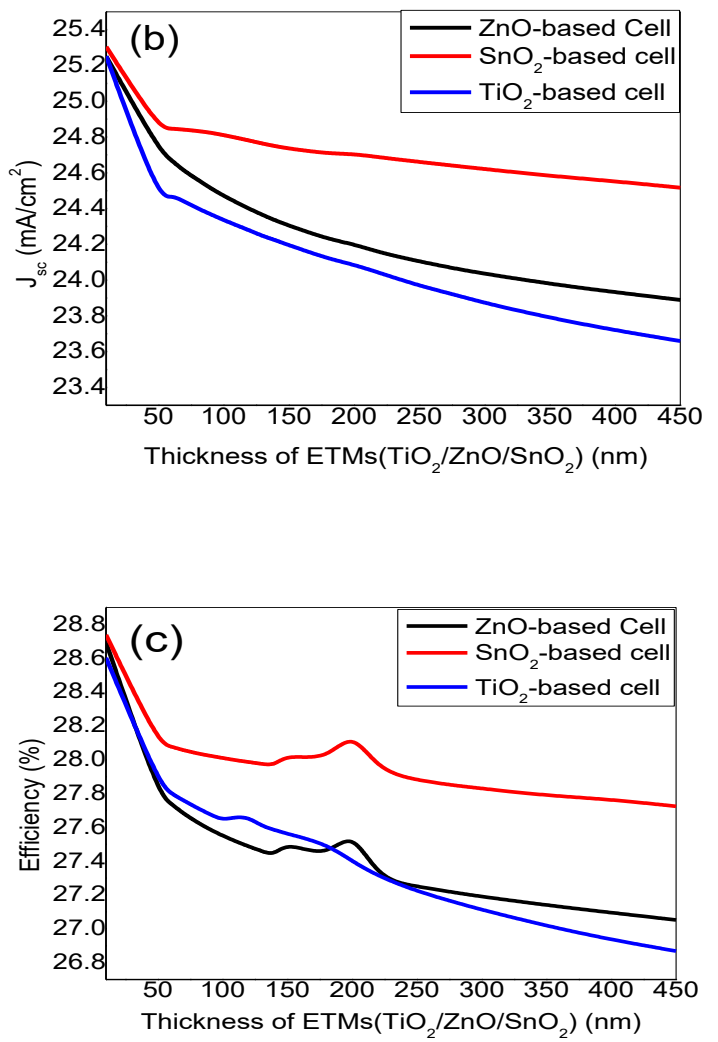

Fig. 4. Photovoltaic performances of three models by varying thickness of ETM (a) Open circuit voltage; (b) Short circuit current density; (c) Photovoltaic conversion efficiency.

\section{Variation of HTM Thickness}

Fig.5 depicts variation of open circuit voltage $\left(\mathrm{V}_{\mathrm{oc}}\right)$, short circuit current density $\left(\mathrm{J}_{\mathrm{sc}}\right)$ and photovoltaic conversion efficiency (PCE) with thickness of spiro-OMeTAD (HTM) layer for all three models. Results are obtained for $90 \mathrm{~nm}$ thickness of ETMs and $400 \mathrm{~nm}$ of $\mathrm{MAPbI}_{3}$ (absorber).

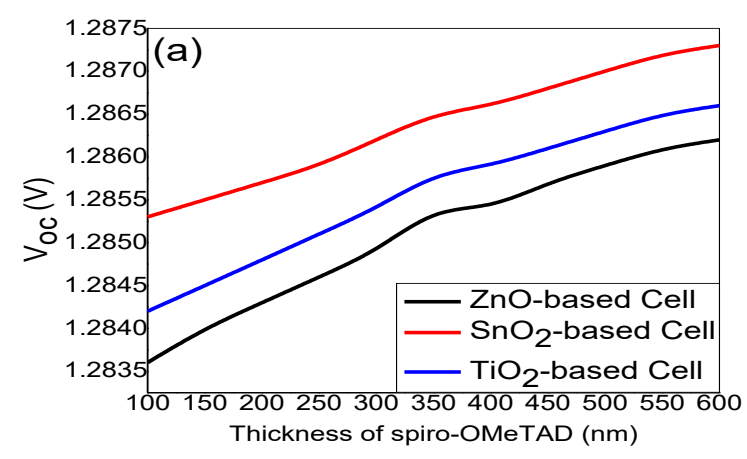

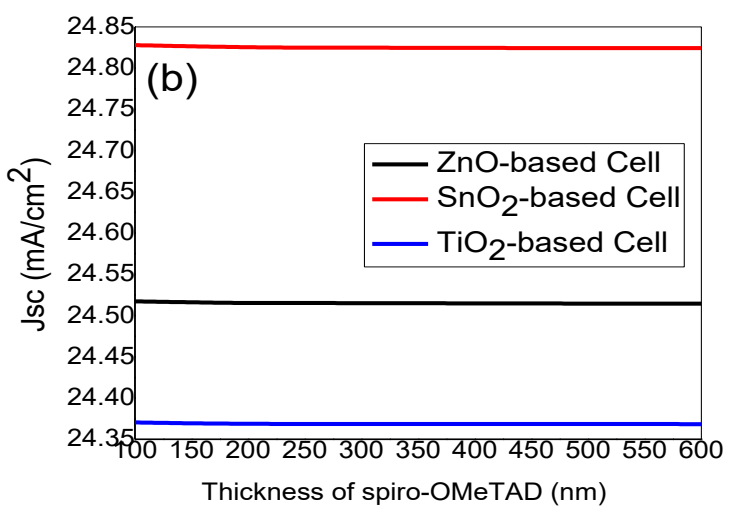

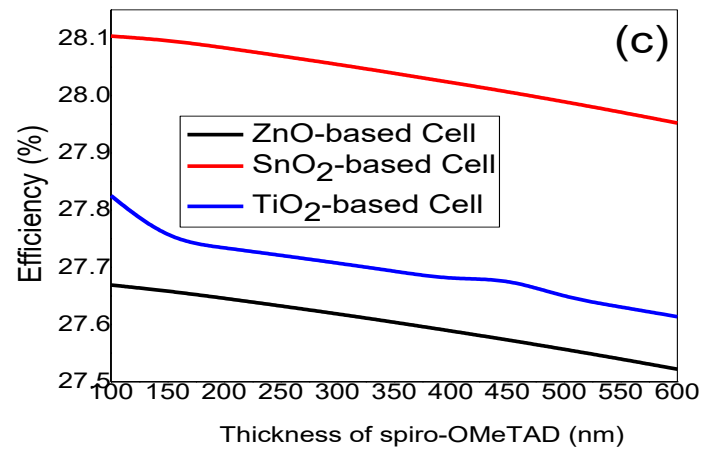

Fig. 5. Photovoltaic performances of three models by varying thickness of HTM (a) Open circuit voltage; (b) Short circuit current density; (c) Photovoltaic conversion efficiency.

$\mathrm{V}_{\mathrm{oc}}$ increases almost linearly with HTM layer for the three models and is higher for $\mathrm{SnO}_{2}$-based cell. HTM layer thickness has a very little effect on $\mathbf{J}_{\mathrm{sc}}$ and efficiencies decrease slightly with increase in HTM thickness. Since the variation of efficiency with HTM layer thickness for all the three models is very small for the entire thickness range, it is wise to take $400 \mathrm{~nm}$ of thickness considering mechanical robustness of the device. The overall photovoltaic performance of $\mathrm{SnO}_{2}$-based cell is better than that of other two cells.

\section{Variation of Absorber Thickness}

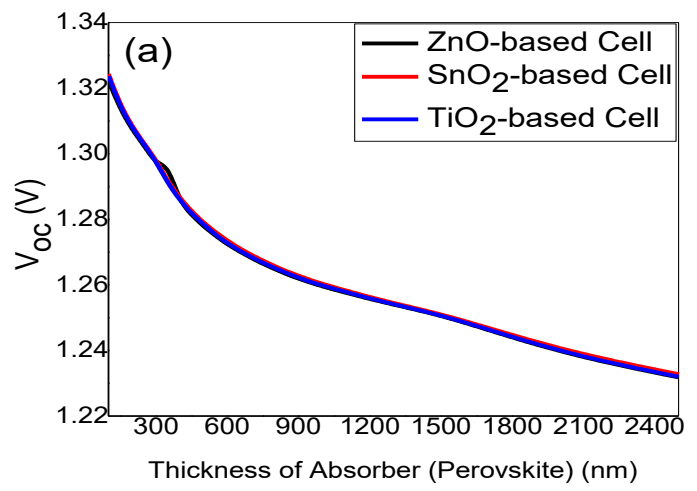



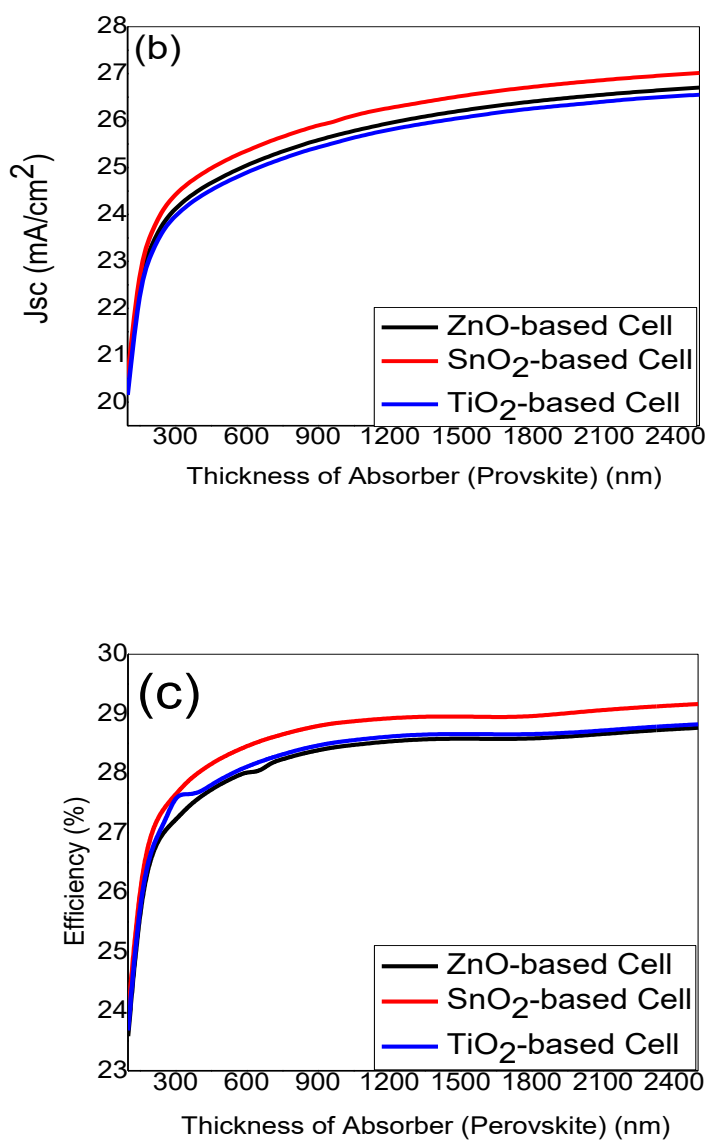

Fig. 6. Photovoltaic performances of three models by varying thickness of absorber (a) Open circuit voltage; (b) Short circuit current density; (c) Photovoltaic conversion efficiency.

Fig. 6 shows variation of open circuit voltage $\left(\mathrm{V}_{\mathrm{oc}}\right)$, short circuit current density $\left(\mathrm{J}_{\mathrm{sc}}\right)$ and photovoltaic conversion efficiency (PCE) with thickness of perovskite $\left(\mathrm{MAPbI}_{3}\right)$ as absorber layer for three models. Cells performances are observed for $90 \mathrm{~nm}$ thickness of ETMs and $400 \mathrm{~nm}$ thickness of HTM layer. $\mathrm{V}_{\text {oc }}$ decreases almost exponentially while $\mathrm{J}_{\mathrm{sc}}$ increases exponentially with the thickness of absorber for all the three models. $\mathrm{J}_{\mathrm{sc}}$ for $\mathrm{SnO}_{2}$-based cell is found comparatively higher than other two models. Efficiency increases sharply for thickness range of $100 \mathrm{~nm}$ to $350 \mathrm{~nm}$. At $350 \mathrm{~nm}$, efficiencies of $27.6 \%, 27.4 \%$ and $27.8 \%$ are found for $\mathrm{TiO}_{2^{-}}, \mathrm{ZnO}-$ and $\mathrm{SnO}_{2}$-base cell respectively. Efficiencies increase in a comparatively smaller rate up to $600 \mathrm{~nm}$ and after that it increases slightly for all the three cells. At $600 \mathrm{~nm}$, efficiencies of $28.1 \%$, $28.02 \%$ and $28.4 \%$ are attained for $\mathrm{TiO}_{2^{-}}, \mathrm{ZnO}-$ and $\mathrm{SnO}_{2-}$ base cell respectively. All the three models give moderately good performance at the thickness of $400 \mathrm{~nm}$. The thickness of the absorber is one of the key factors that mostly affect the rate of photo-generation of charge carriers in addition with the amount of light reaching and absorption range ${ }^{2}$. Beyond this thickness efficiency is increased very slowly in all the three cases as enhancing the thickness after a certain point might increase the series resistance with more rapid rate. The overall performance of $\mathrm{SnO}_{2}$-based cell is higher than other two and $\mathrm{TiO}_{2}$-based cell gives somewhat better performances than $\mathrm{ZnO}$-based cell.

\section{Result Analysis}

This research work investigates the three models of perovskite solar cells with three different ETMs $\left(\mathrm{TiO}_{2}\right.$, $\mathrm{ZnO}, \mathrm{SnO}_{2}$ ). The effect of material properties on performances of perovskite solar cells are simulated and analyzed in detail. Better photovoltaic performances are achieved for lower thickness of ETM layer, but extreme lower thickness may reduce the robustness of device. It has also been explored that increase in absorber thickness has increased the PCE. But if the perovskite absorber layer is too thick, it becomes unfavorable for photo-generated charge carriers to be transported out, which in turn reduces it performances. An optimum thickness is chosen by balancing between its absorption length and diffusion lengths. Moderately higher efficiencies have been found at $400 \mathrm{~nm}$ thickness of absorber, $90 \mathrm{~nm}$ thickness of ETM and $400 \mathrm{~nm}$ of HTM for the three models. Efficiencies of 27.6 $\%, 27.5 \%$ and $28.02 \%$ are found for $\mathrm{TiO}_{2^{-}}, \mathrm{ZnO}-$ and $\mathrm{SnO}_{2^{-}}$ base cell respectively.

Among the three models, $\mathrm{SnO}_{2}$-based cell has provided the best performance for entire thickness range of ETM layer. $\mathrm{SnO}_{2}$ is an attractive electron collecting material for perovskite solar cell with FTO contact to enhance the performance. Compared to $\mathrm{TiO}_{2}, \mathrm{SnO}_{2}$ has higher electron mobility and deeper conduction band. This could accelerate the transportation of charge carriers from perovskite to electron transport layer, and also reduce the carrier accumulation at the surface ${ }^{22}$. On the other hand, although $\mathrm{ZnO}$-based cell gives somewhat lower performance than $\mathrm{TiO}_{2}$-base cell, considering its lower cost, availability and higher electron mobility, $\mathrm{ZnO}$ can also be a good alternative of $\mathrm{TiO}_{2}$ for perovskite solar cell. Also appropriate synthesizing of absorber, best selection of contact materials, and increasing conductivity of ETMs uplift the performance as well as stability of device.

\section{Acknowledgement}

The authors thank Bernabé Marí Soucase for a critical reading of the manuscript. Also thank Prof. Rockett, Dr. Yiming Liu of UIUC and Prof. Fonash of PSU for wxAMPS simulator.

\section{References}

1. Yecheng Zhou and Angus Gray-Weale, 2016. A numerical model for charge transport and energy conversion of perovskite solar cells, Phys.Chem.Chem.Phys.,18, 4476.

2. Krishna R. Adhikari, ShekharGurung, Binod K. Bhattarai and Bernabe Mari Soucase, 2016. Comparative study on MAPbI3 based solar cells using different electron transporting materials, P hys. Status Solidi C 13, ( 1), 13- 17.

3. Feng Liu, Jun Zhu, Junfeng Wei, Yi Li, Mei Lv, Shangfeng Yang, Bing Zhang, Jianxi Yao, and Songyuan Dai, 2014. Numerical simulation: Toward the design of high-efficiency planar perovskite solar cells, Applied Physics Letters 104, 253508 . 
4. Salau, A.M. 1980. Fundamental absorption edge in $\mathrm{PbI}_{2}: \mathrm{KI}$ alloysSol. Energy Mater. 2(3), 327-332.

5. Yutao Zhang, YiminXuyan, 2016. Comprehensive design of omnidirectional high-performance perovskite solar cells,Scientific Reports 6, 29705.

6. Regan, B. O’ M. Grätzel, 1991. A low-cost, high-efficiency solar cell based on dye-sensitized colloidal $\mathrm{TiO}_{2}$ filmsNature $353,737$.

7. EcolePolytechniqueFédérale de Lausanne, 2008. New Efficiency Benchmark For Dye-sensitized Solar Cells, ScienceDaily.

8. Miyasaka, T. 2009. A. Kojima, K. Teshima and Y. Shirai, Organometal Halide Perovskites as Visible-Light Sensitizers for Photovoltaic Cells, J. Amer. Chem. Soc. 131 (17), 60506051.

9. NREL efficiency chart, 2014. last retrieved on 27 September.

10. IBM and Tokyo Ohka Kogyo Turn Up Watts on Solar Energy Production, IBM.

11. CleanTechnica.com, 2014. New CIGS Solar Cell Record: 21.7\% CIGS Cell Conversion Efficiency Achieved At ZSW, last retrieved on 27 September.

12. Yablonovitch, Eli; Miller, Owen D.; Kurtz, S. R. 2012. The opto-electronic physics that broke the efficiency limit in solar cells. 2012 38th IEEE Photovoltaic Specialists Conference.

p. 001556. doi:10.1109/PVSC.2012.6317891. ISBN 978-14673-0066-7.

13. Triple-Junction Terrestrial Concentrator Solar Cells. (PDF). 2012. Retrieved on 3 January.

14. Clarke, Chris (19 April 2011) San Jose Solar Company Breaks Efficiency Record for PV. Optics.org. Retrieved on 19 January 2011

15. Mingzhen Liu, Michael B. Johnston \& Henry J. Snaith, 2013. Efficient planar hetero-junction perovskite solar cells by vapour deposition, 9 september /501/nature/395.
16. Weijun Ke, Guojia Fang ${ }^{*}$, Jing Wang, Pingli Qin, Hong Tao, Hongwei Lei, Qin Liu, Xin Dai, and Xingzhong Zhao, 2014. Perovskite Solar Cell with an Efficient $\mathrm{TiO}_{2}$ Compact FilmACS Appl. Mater. Interfaces6 (18), 15959-15965.

17. Jing Wang, Minchao Qin, Hong Tao, WeijunKe, Zhao Chen, Jiawei Wan, Pingli Qin, Liangbin Xiong, Hongwei Lei, Huaqing Yu and Guojia Fang, 2015. Performance enhancement of perovskite solar cells with $\mathrm{Mg}$-doped $\mathrm{TiO}_{2}$ compact film as the hole-blocking layer, Appl. Phys. Lett. 106, 121104.

18. Yun-Jeong Kim, Tran-Van Dang, Hyung-Jin Choi, ByeongJu Park, Ji-Ho Eom, Hyun-A Song, DaeheeSeol, Yunseok Kim, Sung-Ho Shin, Junghyo Nah and Soon-Gil Yoon, 2016. Piezoelectric properties of $\mathrm{CH} 3 \mathrm{NH} 3 \mathrm{PbI} 3$ perovskite thin films and their applications in piezoelectric generators $\mathrm{J}$. Mater. Chem. A, , 4,75.

19. AoZang, Yulin Chen and Jun Yan, 2016. Optimal Design and High-Performance Organic-Metal Halide perovskite solar cell, IEEE journal of Quantum Electronics, 52, 6.

20. Yiming Liu, Yun Sun, Angus Rockett, 2012. A new simulation software of solar cell - wxAMPS, Volume 98, $124-128$

21. F. Behrouznejad, S. Shahbazi, N. Taghavinia, Hui-Ping Wud and Eric Wei-GuangDiau, J. Mater, 2016. A study on utilizing different metals as the back contact of $\mathrm{CH}_{3} \mathrm{NH}_{3} \mathrm{PbI}_{3}$ perovskite solar cells, Chem. A, 4,13488.

22. Q.Jiang, L.Zhang, H. Wang, X.Yang, J. Meng, H.Liu, Z. Yin, J. Wu, X. Zhang \&J.You, 2016. Enhanced electron extraction using $\mathrm{SnO}_{2}$ for high-efficiency planar-structure $\mathrm{HC}\left(\mathrm{NH}_{2}\right)_{2} \mathrm{PbI}_{3}$-based perovskite solar cells, Nat. Energy.

23. Sultana, N.A., M.O.Islam and Z.H. Mahmood, 2017. "Utilization of low cost metals as back contact with perovskite solar cell", Dhaka University Journal of Applied Science \& Engineering, ISSN 2218-7413, DUJASE. 4(1), 35-38. 